Case Study

\title{
Changes in thoracic and lumbar spinal motions during running in a female with scoliosis
}

\author{
Michio Tojima, PhD, $\mathrm{PT}^{1,2)^{*}}$, Ayaka Osada, BSc ${ }^{3)}$, Suguru ToriI, PhD, MD ${ }^{4)}$ \\ 1) Waseda Institute for Sport Sciences, Japan \\ 2) Tokyo International University: 2509 Matoba, Kawagoe, Saitama 350-1198, Japan \\ 3) School of Sport Sciences, Waseda University, Japan \\ 4) Faculty of Sport Sciences, Waseda University, Japan
}

\begin{abstract}
Purpose] The aim of this study was to analyze changes in thoracic and lumbar spinal motions during running in a female athlete with scoliosis. [Participant and Methods] A female with scoliosis who was a member of a college track team was recruited for this study. On 1.5-T magnetic resonance imaging, angles between bodies of adjacent vertebrae in the frontal plane were calculated. We measured real-time spine movement while running using a three-dimensional motion analysis system, wherein the running speed was altered $(6,9$, and $12 \mathrm{~km} / \mathrm{h})$. [Results] We observed a Cobb angle of $29.0^{\circ}$ and the right convex curvature of the thoracolumbar spine on magnetic resonance imaging. As the running speed increased, during the right stance phase, the participant increased the lateral bending angle of the thoracic spine to the left and the lumbar spine to the right. However, during the left stance phase, the runner bent the thoracic spine to the right and the lumbar spine to the left, indicating a decreased convex curvature of the spine. [Conclusion] As the running speed increased, the convex curvature of the spine was corrected during the left stance phase but was uncorrected during the right stance phase.

Key words: Adolescent idiopathic scoliosis, Running, Spine
\end{abstract}

(This article was submitted Apr. 25, 2019, and was accepted Jul. 27, 2019)

\section{INTRODUCTION}

Adolescent idiopathic scoliosis (AIS) is characterized by a three-dimensional (3D) curvature of the spine ${ }^{1)}$. Over $40 \%$ of individuals with scoliosis returned to sports at a level lower than preoperative participation levels or did not return at all following spinal fusion ${ }^{2}$.

There are some reports for measuring spine movement of AIS using motion analysis during trunk motion with standing positon $^{3-5)}$ and gait ${ }^{6,7)}$. With increasing the running speed, the movement of lumbar spine was increased to extend, laterally bend, and rotate in healthy runners ${ }^{8-10)}$. However, there were no reports for measuring 3D movement of spine in AIS during running. The aim of this study was to analyze the change in thoracic and lumbar spinal motion in a female athlete with scoliosis during running, which could contribute to athletic rehabilitation.

\section{PARTICIPANT AND METHODS}

A female participant with scoliosis (age, 21 years; height, $156.0 \mathrm{~cm}$; body mass, $46.0 \mathrm{~kg}$; and body mass index, $18.9 \mathrm{~kg} /$ $\mathrm{m}^{2}$ ) on a college track team was recruited in this study. This study was approved by the Office of Research Ethics, Waseda University (No. 2016-098). An informed consent was obtained from the participant.

To avoid radiation exposure, a 1.5-T Magnetic resonance imaging (MRI, Signa Excite Xi, GE Healthcare UK Ltd., Buck-

*Corresponding author. Michio Tojima (E-mail: mtojima@tiu.ac.jp)

(C2019 The Society of Physical Therapy Science. Published by IPEC Inc.

(c) (1) $\odot$ This is an open-access article distributed under the terms of the Creative Commons Attribution Non-Commercial No DerivaCC BY NC ND tives (by-nc-nd) License. (CC-BY-NC-ND 4.0: https://creativecommons.org/licenses/by-nc-nd/4.0/) 
inghamshire, UK) was used to calculate the Cobb angle of the spine in the neutral spine position. A body coil was utilized to obtain T2-weighted fast spin-echo frontal images from the thoracic to lumbar spine (echo time, $80.5 \mathrm{~ms}$; repetition time, 7,059 ms; slice thickness, $7 \mathrm{~mm}$; interslice gap, $1.4 \mathrm{~mm}$; field of view, $480 \times 480 \mathrm{~mm}$; and resolution, $320 \times 192 \mathrm{pix}$ ).

After a 3-min warm-up, the participant's clothing and back surfaces were immobilized using a bilateral tape, followed by placement of 68 spherical markers on each anatomical landmark (Fig. 1). Based on a previous spine measurement methodology ${ }^{11)}$, eight original spherical markers were placed at the following anatomical landmarks: (1) right and left paravertebral muscles at the first thoracic vertebra (T1), T2, and seventh cervical vertebra to represent an upper thoracic segment and (2) right and left paravertebral muscles at the T11, T10, and T12 to represent a thoracolumbar segment. Real-time running motion was measured using a 3D motion analysis system (Qualisys Track Manager, Qualisys AB, Göteborg, Sweden) with eight cameras set at $250 \mathrm{~Hz}$. The participant was instructed to run on a treadmill (IGNIO R-16S, Alpen Co. Ltd., Aichi, Japan), and the running speeds were altered in the following order: 6,9 , and $12 \mathrm{~km} / \mathrm{h}$.

Noise was filtered from the raw data using a 6-Hz low-pass filter. The biomechanics analysis software Visual3D (version 5; C-Motion Inc., MD, USA) was used to calculate the angle of the thoracic and lumbar spine ${ }^{11)}$. The thoracic spine angle was calculated from the upper thoracic segment with respect to the thoracolumbar segment (i.e., sum of T3-9 vertebral movements), as well as the lumbar spine angle from the thoracolumbar segment with respect to the pelvic segment (i.e., sum of L1-5 vertebral movements).

Data were collected for the following four events: right foot contact, right toe off, left foot contact, and left toe off. From the right foot contact to the next right foot contact, data of 10 cycles were averaged for one participant into one cycle, and these one-cycle data were converted into a percentage.

\section{RESULTS}

The participant with AIS showed right convex curvature of the thoracolumbar spine. In the supine position, a Cobb angle of $29.0^{\circ}$ was shown in the MRI (Fig. 2). In the upright position, the motion analysis showed the thoracic/lumbar spine were flexed $2.0^{\circ}$ extended $21.4^{\circ}$, bended laterally to left in $5.3^{\circ} /$ right in $3.5^{\circ}$, and rotated to right $0.4^{\circ} /$ left in $1.2^{\circ}$, respectively.

As the running speed increased, the stance phase was shortened by $9.8 \%$ at the right side and by $6.3 \%$ at the left side (Table 1). Further, during the right stance phase, the participant increased lateral bending angle of the thoracic spine to the left and of the lumbar spine to the right, indicating an increased convex curvature of the spine (Fig. 3 and Table 2). During the early left stance phase, the participant showed an increased lateral bending angle of the thoracic spine to the right and of

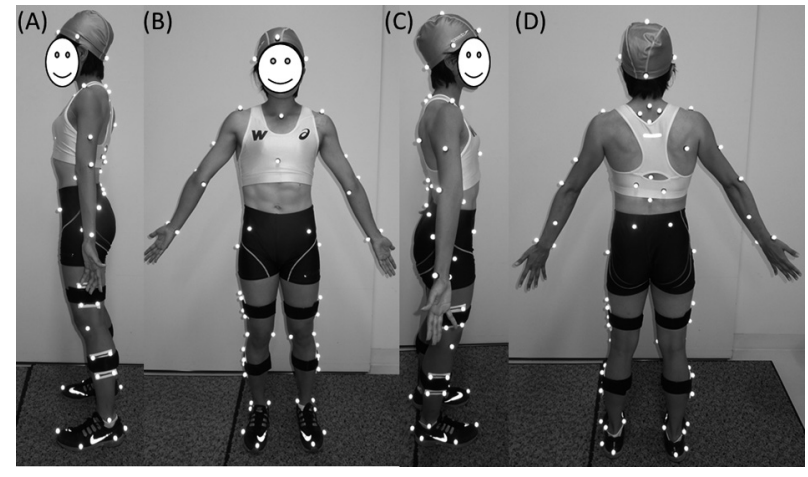

Fig. 1. Sites of the 68 reflective markers on the whole body.



Fig. 2. Magnetic resonance imaging of a female runner with scoliosis in the frontal plane.

The upper thoracic spine (T1/2-T6/7) bent to the left by $17.5^{\circ}$, lower thoracic spine (T7/8-L1/2) bent to the right by $47^{\circ}$, and lumbar spine (L2/3-L5/sacrum) bent to the left by $14.0^{\circ}$. 
the lumbar spine to the left, indicating a decreased convex curvature of the spine (Fig. 3). As the running speed increased, it was increased that the rotation angle of thoracic spine to left in the late right stance phase and the rotation angle of lumbar spine to right in the late left stance phase (Fig. 3).

\section{DISCUSSION}

Based on the MRI, the participant exhibited a right convex curvature of the thoracolumbar spine. As the running speed increased, the convex curvature of the spine was corrected during the left stance phase but was uncorrected during the right stance phase. With increasing the running speed, healthy female runners increased rotation and lateral bending angle of the spine $^{9)}$. In this study, the participant could control the lateral bending angle of spine; therefore she would maintain the balance and increase the running speed in the stance phase.

During the right stance phase, the participant bent the thoracic and lumbar spines in opposite directions, which increased

Table 1. Change of each time parameter (\%) during running

\begin{tabular}{llccc}
\hline & & $6 \mathrm{~km} / \mathrm{h}$ & $9 \mathrm{~km} / \mathrm{h}$ & $12 \mathrm{~km} / \mathrm{h}$ \\
\hline Stance phase & Right & 37.8 & 29.5 & 28.0 \\
& Left & 35.6 & 31.2 & 29.3 \\
& Both & 73.3 & 60.7 & 57.3 \\
Swing phase & Right & 12.8 & 22.0 & 22.0 \\
& Left & 13.9 & 17.3 & 20.7 \\
\multirow{3}{*}{ Right toe off } & Both & 26.7 & 39.3 & 42.7 \\
Left foot contact & & 37.8 & 29.5 & 28.0 \\
Left toe off & & 50.6 & 51.4 & 50.0 \\
\hline
\end{tabular}

The first time (\%) was the right foot contact and last was the next right foot contact.

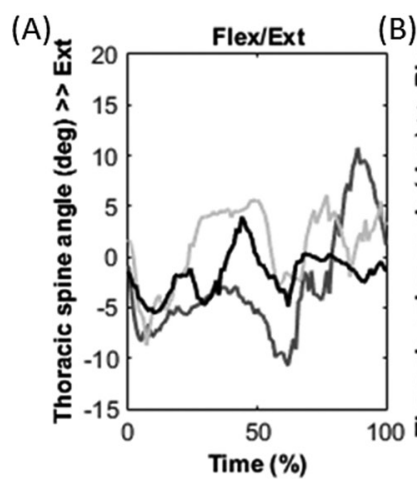

(D)

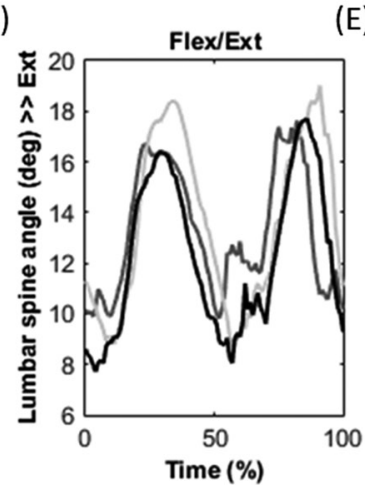

(E)


(F)

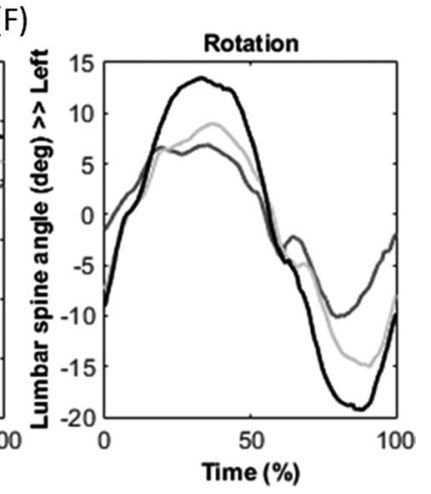

Fig. 3. The mean of 10 cycles of thoracic (A to C) and lumbar (D to F) spine angle during running. Dark gray lines, $6 \mathrm{~km} / \mathrm{h}$; light gray lines, $9 \mathrm{~km} / \mathrm{h}$; black lines, $12 \mathrm{~km} / \mathrm{h}$; Ext, extension; Flex, flexion. Increase in absolute value for the positive/negative values denotes increasing angles of extension/flexion, lateral bending to right/left, and rotation to left/right, respectively. The time of $0 \%$ and $100 \%$ denote the right foot contact and the next right foot contact respectively. 
Table 2. Change of thoracic and lumbar spine angle during running

\begin{tabular}{|c|c|c|c|c|c|}
\hline & & & $\begin{array}{c}6 \mathrm{~km} / \mathrm{h} \\
\text { mean } \pm \mathrm{SD}\end{array}$ & $\begin{array}{c}9 \mathrm{~km} / \mathrm{h} \\
\text { mean } \pm \mathrm{SD}\end{array}$ & $\begin{array}{c}12 \mathrm{~km} / \mathrm{h} \\
\text { mean } \pm \mathrm{SD}\end{array}$ \\
\hline \multirow{9}{*}{$\begin{array}{l}\text { Thoracic } \\
\text { spine }\end{array}$} & \multirow[t]{3}{*}{ Flex/Ext } & Range & $21.8 \pm 8.1$ & $15.5 \pm 5.5$ & $9.7 \pm 2.2$ \\
\hline & & Ext & $11.1 \pm 4.2$ & $6.8 \pm 6.6$ & $4.1 \pm 2.8$ \\
\hline & & Flex & $-10.7 \pm 11.9$ & $-8.8 \pm 4.3$ & $-5.6 \pm 1.6$ \\
\hline & \multirow[t]{3}{*}{ Lateral bend } & Range & $8.5 \pm 1.6$ & $7.2 \pm 1.6$ & $8.5 \pm 1.4$ \\
\hline & & Left & $-10.3 \pm 1.0$ & $-9.5 \pm 1.7$ & $-12.2 \pm 1.4$ \\
\hline & & Right & $-1.8 \pm 2.2$ & $-2.3 \pm 1.5$ & $-3.7 \pm 1.3$ \\
\hline & \multirow[t]{3}{*}{ Rotation } & Range & $8.4 \pm 1.3$ & $11.3 \pm 2.9$ & $19.2 \pm 2.7$ \\
\hline & & Left & $7.4 \pm 1.1$ & $10.0 \pm 1.3$ & $11.7 \pm 2.0$ \\
\hline & & Right & $-1.0 \pm 1.4$ & $-1.3 \pm 4.6$ & $-7.5 \pm 3.4$ \\
\hline \multirow{9}{*}{$\begin{array}{l}\text { Lumbar } \\
\text { spine }\end{array}$} & \multirow[t]{3}{*}{ Flex/Ext } & Range & $8.1 \pm 1.1$ & $10.5 \pm 1.9$ & $10.1 \pm 1.2$ \\
\hline & & Ext & $17.7 \pm 1.4$ & $19.2 \pm 2.8$ & $17.8 \pm 1.5$ \\
\hline & & Flex & $9.6 \pm 0.8$ & $8.7 \pm 0.9$ & $7.7 \pm 0.9$ \\
\hline & \multirow[t]{3}{*}{ Lateral bend } & Range & $12.1 \pm 1.0$ & $14.5 \pm 1.3$ & $19.4 \pm 1.8$ \\
\hline & & Left & $-2.6 \pm 1.2$ & $-3.3 \pm 1.2$ & $-5.0 \pm 1.8$ \\
\hline & & Right & $9.5 \pm 0.8$ & $11.2 \pm 1.4$ & $14.5 \pm 1.8$ \\
\hline & \multirow[t]{3}{*}{ Rotation } & Range & $17.1 \pm 0.8$ & $24.1 \pm 1.0$ & $32.8 \pm 2.0$ \\
\hline & & Left & $6.9 \pm 1.0$ & $9.0 \pm 0.9$ & $13.5 \pm 2.2$ \\
\hline & & Right & $-10.2 \pm 0.6$ & $-15.1 \pm 1.1$ & $-19.4 \pm 1.8$ \\
\hline
\end{tabular}

Ext: extension; Flex: flexion.

Increase in absolute value for the negative values denotes increasing angles of flexion, lateral bending to the left, and rotation to the right, respectively.

the convex curvature of the spine and served to decrease the right stance phase time. However, this runner also bent the thoracic spine to the right and the lumbar spine to the left during the left stance phase, leading to the correction of the convex curvature of the spine. Comparison with healthy runners ${ }^{8-10)}$, the participant increased the convex curvature of spine during right stance phase. To prevent the degeneration of spine alignment, attention must be paid to the phase wherein the convex curvature of the spine increases. In the athletic rehabilitation, trainers and therapists should train the athlete with AIS to trunk muscles controlling the spine movement and the balance during high speed running.

As a limitation of this study, it was unable to clearly concluded the effect of running on the degeneration of spine alignment from only one runner with scoliosis. Future studies should longitudinally observe the effect of running in a larger sample of male and female runners with scoliosis in an AIS-prone age group.

\section{Conflict of interest}

All authors have no conflicts of interest to disclose.

\section{Funding}

None.

\section{REFERENCES}

1) Weinstein SL, Dolan LA, Cheng JC, et al.: Adolescent idiopathic scoliosis. Lancet, 2008, 371: 1527-1537. [Medline] [CrossRef]

2) Kakar RS, Simpson KJ, Das BM, et al.: Review of physical activity benefits and potential considerations for individuals with surgical fusion of spine for scoliosis. Int J Exerc Sci, 2017, 10: 166-177. [Medline]

3) Udoekwere UI, Krzak JJ, Graf A, et al.: Effect of lowest instrumented vertebra on trunk mobility in patients with adolescent idiopathic scoliosis undergoing a posterior spinal fusion. Spine Deform, 2014, 2: 291-300. [Medline] [CrossRef]

4) Engsberg JR, Lenke LG, Reitenbach AK, et al.: Prospective evaluation of trunk range of motion in adolescents with idiopathic scoliosis undergoing spinal fusion surgery. Spine, 2002, 27: 1346-1354. [Medline] [CrossRef]

5) Galvis S, Burton D, Barnds B, et al.: The effect of scoliotic deformity on spine kinematics in adolescents. Scoliosis Spinal Disord, 2016, 11: 42. [Medline] [CrossRef]

6) Schmid S, Studer D, Hasler CC, et al.: Quantifying spinal gait kinematics using an enhanced optical motion capture approach in adolescent idiopathic scoliosis. Gait Posture, 2016, 44: 231-237. [Medline] [CrossRef] 
7) Mahaudens P, Banse X, Mousny M, et al.: Gait in adolescent idiopathic scoliosis: kinematics and electromyographic analysis. Eur Spine J, 2009 , 18: 512-521. [Medline] [CrossRef]

8) Schache AG, Blanch PD, Rath DA, et al.: Intra-subject repeatability of the three dimensional angular kinematics within the lumbo-pelvic-hip complex during running. Gait Posture, 2002, 15: 136-145. [Medline] [CrossRef]

9) Tojima M, Osada A, Torii S: Changes in hip and spine movement with increasing running speed. J Phys Ther Sci, 2019, 31: 661-665. [Medline]

10) Saunders SW, Schache A, Rath D, et al.: Changes in three dimensional lumbo-pelvic kinematics and trunk muscle activity with speed and mode of locomotion. Clin Biomech (Bristol, Avon), 2005, 20: 784-793. [Medline] [CrossRef]

11) Tojima M, Torii S: Changes in lumbopelvic rhythm during trunk extension in adolescent soccer players. Gait Posture, 2017, 52: 72-75. [Medline] [CrossRef] 